\title{
SCHLOMO IBN GABIROL (AVICEBRON) A FONTE DA VIDA - TRATADO PRIMEIRO
}

\author{
Tradução: Cecilia Cintra Cavaleiro de Macedo
}

\section{Das coisas prévias para a determinação da matéria universal e da forma universal e para a determinação da matéria e da forma nas substâncias compostas.}

1.

Mestre - Posto que, graças a teu talento e tua aplicação ao estudo, obtiveste já tanto proveito, começa a perguntar-me acerca das questões que mais te aprouverem. Mas busca chegar até a última pergunta, que indaga a razão pela qual o homem foi criado. Quanto ao modo de nosso colóquio, que seja por perguntas e respostas, de acordo com as regras da demonstração.

Discípulo - Como poderemos ordenar a sucessão de perguntas e respostas de acordo com as regras lógicas de demonstração, sem muito dispêndio de tempo e sem necessidade de muita preparação?

M. - Tens razão. Proponhamos, pois, as argumentações e proposições isoladas sobre aquilo que buscamos na medida em que elas se nos apresentem, até que comecemos a organizá-las de acordo com as regras lógicas, depois de termos definido os termos, e depois da compreensão de tudo o que se refere a eles, seja em si mesmos, seja em sua maneira de ser. Mas se, por acaso, chegarmos a tratar alguma destas questões de acordo com as regras da dialética, fá-lo-emos sem levar em consideração a ordem dos termos nas proposições, pois isso nos desviaria de nossa meta desde o princípio.

D. - Já há tempos conheces meu apreço pela arte da demonstração e meu zelo com relação a ela. Mas, como tenho a alma repleta de numerosos problemas, temo que meu conhecimento acerca da demonstração seja insuficiente para compreender a veracidade de todas estas questões.

M. - Na medida em que concedas à arte da lógica aquilo que lhe é devido e que não te apresses demais em julgar as coisas, não deves temer encontrar entre estas questões algumas que te falte conhecimento para demonstrar sua veracidade.

D. - Demonstra-me para que me assegure disso.

\begin{tabular}{|l|l|l|l|l|l|}
\hline VERITAS & Porto Alegre & v. 50 & n. 3 & Setembro 2005 & p. 159-172 \\
\hline
\end{tabular}


M. - É preciso que dividas as coisas em duas classes. Há algumas coisas que o homem é capaz de conhecer, ou seja, aquelas que caem sob a inteligência humana; e há outras que não lhe é possível conhecer, posto que a ultrapassam. Daquelas que ele pode conhecer, algumas conhece necessariamente, pois são evidentes por si, e outras não. Para conhecer as que são evidentes por si, não há necessidade de demonstração, enquanto que ao conhecimento daquelas que não são evidentes por si chega-se através das demonstrações. E, tendo o cuidado de observar suas regras, ou seja, as regras da arte da dialética, pode-se obter a certeza da investigação.

\section{2.}

D. - Muito me satisfez tua resposta e estou instigado a aprofundar meu conhecimento na ciência da lógica. Mas agora desejo perguntar-te acerca dos problemas que creio serem os mais necessários, pois a bondade de tua alma proporcionou-me a ousadia de indagá-los.

M. - Pergunta-me sobre o que quiseres, pois estou disposto a satisfazer-te.

D. - O que o homem deve buscar nesta vida?

M. - Posto que a parte cognoscente é a melhor entre as porções do Homem, o que o homem deve buscar acima de tudo é o conhecimento. Mas o que, desta ciência, é mais necessário que busque é conhecer a si mesmo, a fim de, através disso, chegar ao conhecimento das outras coisas que estão fora dele mesmo. Porque como sua essência envolve as coisas e as penetra, e as coisas estão submetidas a seu poder, deve buscar através dela a causa final pela qual foi criado, e é preciso que a estude profundamente, pois é dessa maneira que poderá alcançar a felicidade;

D. - Por que a essência do homem possui uma causa final?

M. - Como não haveria de ser assim, quando todas as coisas estão submetidas à vontade do Uno Altíssimo?

D. - Explica-me isso.

M. - Posto que a Vontade é a virtude divina que tudo cria e que tudo move, logo, é impossível que algo se faça sem ela.

D. - Como é isso?

M. - Posto que o movimento pelo qual todas as coisas são produzidas está ligado à Vontade, é necessário que o movimento das coisas dependa do movimento da Vontade e o repouso das coisas, ao repouso da Vontade.

D. $-\mathrm{E}$ o que se deduz disso?

M. - Disso se deduz que o repouso e o movimento na geração do homem e dos demais seres são causados pela ação da vontade.

D. - Qual é, pois, a causa final da geração do homem?

M. - A aproximação de sua alma ao mundo mais elevado, para que cada coisa retorne ao que lhe é semelhante.

D. $-\mathrm{E}$ de que modo isso pode ser alcançado? 
M. - Pelo conhecimento e pela ação. Porque é pelo conhecimento e pela ação que a alma se une à vida mais elevada, posto que o conhecimento conduz à ação e a ação separa a alma dos opostos que a danificam e reconduzem-na à sua natureza e à sua essência. Em geral, o conhecimento e a ação libertam a alma de sua servidão à natureza e purificam-na de suas trevas e de sua escuridão; e deste modo a alma regressa à sua vida superior.

3.

D. - Qual é a prova de que a causa da geração do homem é o conhecimento e a ação?

M. - Esta prova se estabelece a partir de sua definição.

D. - Explica-me isso.

M. - Concordas que para aquilo que é perfeito em potência, sua perfeição é tornar ato o que é possível? É necessário, pois, que a causa de seu ser seja tornarse ato.

D. - Não diria outra coisa.

M. - Concordas que a perfeição da alma é o conhecimento de si, sua imperfeição é a ignorância, e que, desde seu surgimento neste mundo, a alma passa da ignorância ao conhecimento e, deste modo, de potência a ato?

D. - Não diria outra coisa.

M. - Posto que a perfeição da alma é passar de potência a ato e que para tudo o que é perfeito em potência e lhe seja possível passar ao ato, a causa de sua essência deve ser que essa perfeição se torne ato; o que se deduz disso?

D. - Deduz-se que a causa da geração do homem é fazer passar o conhecimento da alma de potencial a atual.

M. - Agora já está claro para ti que a causa da geração do homem é o conhecimento.

D. - Sim, dessa maneira, está claro. Mas, demonstra-me por outros meios e estabelece uma regra geral para este assunto.

M. - Considera a essência da alma e a sua forma, pela qual se distingue das demais; observa também a transformação dos elementos em seres e destes seres em outros; presta atenção na composição dos instrumentos da alma cognoscente, ou seja, dos sentidos. Verás em cada um deles as forças ocultas e manifestas da alma. A partir daí obterás as demonstrações adequadas.

4.

D. - Por estas considerações, já está claro para mim que o conhecimento é a causa final da geração do homem. Penso, no entanto, que deveríamos investigar a permanência da alma em si e a ação do conhecimento sobre a alma que o adquire, e quais são os conhecimentos que nela permanecem depois de sua separação do corpo e quais os que não. Mas estas investigações não se referem ao que estamos tratando no momento; já me informei sobre isto quando me dediquei ao conheci- 
mento da alma. Agora, devo perguntar qual é este conhecimento para o qual o homem foi criado?

M. - O Conhecimento para o qual o homem foi criado é o conhecimento de todas as coisas tal como elas são ${ }^{1}$ e, sobretudo, o conhecimento da Essência Primeira que o mantém e o move.

D. - Há um caminho para alcançar o conhecimento da Essência Primeira?

M. - Alcançar este conhecimento não é impossível, mas também não é possível em todos os seus aspectos.

D. - O que é possível e o que é impossível?

M. - Impossível é conhecer a essência primeira sem as criaturas que foram criadas por ela; o que é possível é conhecê-la, mas somente por meio de suas obras.

5.

D. - Por que é impossível o conhecimento da Essência?

M. - Porque está acima de tudo e porque é infinita.

D. - Como então a alma pode conhecer a inteligência que está acima dela?

M. - Porque a inteligência é semelhante à alma e são contíguas, por isso pode conhecê-la; mas a essência primeira não é semelhante à inteligência e não mantém relação alguma com ela, posto que não se relaciona com nenhum dos compostos nem nenhum dos simples; e a relação dos simples para com a essência, na impossibilidade de conhecê-la, é como a relação do composto com o simples, na impossibilidade de conhecê-lo.

D. - Por que a infinitude da essência faz com que seu conhecimento seja impossível?

M. - Porque o conhecimento daquele que conhece consiste na apreensão da coisa conhecida. Por isso é impossível que o conhecimento abarque uma coisa infinita.

D. - Como podemos encontrar um caminho para saber se a Essência existe?

M. - Consideremos primeiro a essência do ser universal e as modificações que pode padecer, e a seguir, o movimento e a vontade que contém e sustenta a essência de todas as coisas.

D. - A essência do ser universal' ${ }^{2}$, é una ou múltipla?

M. - Múltipla, certamente, mas ainda que seja múltipla e diversa, concorda, no entanto, em duas coisas, pelas quais se sustenta e possui o ser.

D. - E quais são estas duas coisas?

M. - A matéria universal e a forma universal.

O que implica necessariamente num conhecimento imperfeito, conforme o autor irá explicar em II, 3.

Aqui, com a denominação ser universal "esse universalis", Ibn Gabirol não se refere a Deus, mas ao ser criado 
D. - Como tudo o que existe concorda nestas duas coisas?

M. - Porque elas são a raiz de tudo e a partir delas foi produzido tudo aquilo que é.

D. - E como estas duas são raiz de tudo o que existe?

M. - Porque por natureza elas precedem todas as coisas e a elas todas as coisas se reduzem.

D. - Como todas as coisas se reduzem a elas?

M. - Porque a matéria primeira universal é a mais simples e o fim último de toda matéria, e do mesmo modo, a forma universal é a mais simples de todas as formas e é unificadora de todas as demais formas.

\section{6.}

D. - Esta redução de todas as coisas se dá em ato ou em pensamento?

M. - Não se dá em ato, mas no pensamento.

D. - Preciso saber, em primeiro lugar, se todas as diferentes coisas se reduzem a uma só raiz ou a duas raízes que se unem, antes de saber se uma delas é a matéria e a outra é a forma.

M. - Já sabes com segurança o que é substância e o que é acidente?

D. - Sim.

M. - Se todas as substâncias concordam em que são substâncias, é necessário que exista uma substância comum a todas, que as una umas às outras e que confira a todas elas igualmente o caráter de substancialidade.

D. - Como podes afirmar isso sabendo que cada uma das substâncias é diferente da outra?

M. - Nenhuma das substâncias é diferente das outras em sua essência.

D. - Qual é a prova disso?

M. - Se as substâncias fossem diferentes quanto a serem substâncias, uma delas não seria substância.

D. - Por que não?

M. - A substancialidade está relacionada à essência; portanto, a substancialidade em si não é variável. Logo, não é possível que a essência se diversifique quanto àquilo em que não é diversa.

D. - Assim é.

M. - Logo, não é impossível reduzir todas as coisas diversas a duas raízes que se juntem.

D. - É certo. Mas por que não afirmar que a raiz de tudo o que é diverso é una?

M. - Se a raiz de todas as coisas diversas fosse una, seria preciso que naquilo em que concordam houvesse diversidade; e ainda que a raiz de tudo fosse uma, seria preciso, entretanto, torná-la dupla em sua própria raiz.

D. - Como assim? 
M. - Se tudo aquilo que dela procede é nomeado por propriedades diversas dela mesma, a raiz mesma deve ser nomeada por uma propriedade que não é ela mesma.

D. - Agora está claro para mim que é necessário que tudo retorne a duas raízes. Mas, qual é a prova de que uma é a matéria universal e a outra é a forma universal, como antes disseste?

M. - Posto que já aceitaste que existem duas raízes às quais tudo se reduz, é preciso que em seguida aceites que uma sustenta e a outra é sustentada.

\section{7.}

D. - Isso me basta. Mas, dado que são duas as raízes de tudo aquilo que é, faz-se necessário que tratemos de investigá-las.

M. - Isso é útil e necessário para o conhecimento da Vontade e para o conhecimento da Essência Primeira.

D. - Por ventura existe outro conhecimento além da ciência da matéria e da forma e da ciência da Essência Primeira?

M. - Sim. Três são as partes de todo o conhecimento, a saber: a ciência da matéria e da forma, a ciência da Vontade e a ciência da Essência Primeira.

D. - Por que são três as partes do conhecimento de tudo?

M. - Porque nada mais há no ser que três coisas: a matéria e a forma, a Essência Primeira e a Vontade que é a intermediária entre estes dois extremos.

D. - E qual é a causa de que no ser nada exista além destas três coisas?

M. - A razão disto é que tudo aquilo que é criado necessita uma causa e algum intermediário entre eles. A causa é a Essência Primeira; o que é criado é matéria e forma; e o intermediário, a Vontade.

D. - Dá-me um exemplo da relação entre elas, isso é, de umas com as outras, e do ordenamento de uma com relação às demais.

M. - A matéria e a forma são como o corpo humano e sua forma, entendendo-se como forma a composição de seus membros; a Vontade é como a alma e a Essência Primeira, como a inteligência.

D, - E qual destas ciências precede as demais?

M. - Para a finalidade de investigação e ensinamento, o conhecimento da matéria e da forma precede o conhecimento da Vontade, o qual precede o conhecimento da Essência Primeira. Mas, de acordo com o ser, ocorre o contrário.

D. - Acreditas que, além destes, nenhum conhecimento há que devamos buscar?

M. - Não. Pois estes conhecimentos são os fundamentos e as raízes da sabedoria, ainda que seus ramos sejam muitos.

D. - Destes conhecimentos, algum deles deriva de outro?

M. - A matéria e a forma são um ramo da Vontade. Mas é impossível dizer-te mais, até que possuas o conhecimento da matéria, da forma e da Vontade. 
8.

M. - Busca primeiro o conhecimento da matéria e da forma, pois esta primeira parte da sabedoria precede, pela ordem, as outras duas.

D. - Faz com que eu alcance um conhecimento seguro da matéria e da forma.

M. - Depois que tenhas aprendido bem a ciência da demonstração lógica, o mais certo e mais útil é que comeces teu estudo pela análise da essência da substância da alma, suas faculdades e seus acidentes, o que lhe corresponde e se relaciona com ela, pois a alma é o sujeito do conhecimento, e ela apreende todas as coisas com suas faculdades que tudo penetram. Se já estudaste isso, está bem, mas se não estudaste ainda, que este seja o início de tua investigação.

D. - Asseguro-te que já há muito tempo dediquei-me ao conhecimento da alma e a seu estudo sutil. Através dele adquiri o conhecimento que me fez ver sua excelência, sua permanência e sua sutileza para compreender tudo; até o ponto em que, ao verificar que sua substância tudo contém, admiro-me de que isso seja possível de alguma maneira.

M. - Observa se tua essência contém tudo o que conheces sobre o que existe, e se aquilo que sabes está fixo em tua essência de algum modo.

D. - Então não sei, vendo que posso englobar o universo inteiro e apreender mais rapidamente que um piscar de olhos? E que não poderia fazer isso se a essência da alma não fosse sutil e forte, se não penetrasse todas as coisas e tudo percebesse.

M. - Se bem conheceste a verdade sobre a essência da alma e representaste sua compreensão de todas as coisas, começa a separar as coisas que existem e reduz os compostos a seus simples, que são a matéria e a forma.

9.

D. - Aprendi sobre a alma tudo o que me foi possível, ainda que não tenha chegado ao limite do que deveria conhecer. Comecemos pois, agora, nossa investigação acerca da matéria universal e da forma universal. Mas, quero que comeces por enumerar os capítulos, quer dizer, os temas que devemos estudar no âmbito da investigação à qual nos encaminhamos e que dividas o assunto de modo racional, para que tenha tudo à mão.

M. - Posto que nosso propósito é estudar a matéria universal e a forma universal, devemos dizer que aquilo que é composto de matéria e forma se divide em dois: a substância corpórea composta e a substância simples espiritual. A substância corpórea se divide em outros dois, pois uma delas é a matéria corpórea que sustenta a forma das qualidades e outra, diferente dela, é a matéria espiritual que sustenta a forma corpórea. Por isso são necessários dois tratados. O primeiro versará sobre o que deve ser estabelecido para designar a matéria universal e a forma universal, para buscar o conhecimento da matéria nas coisas sensíveis e para falar da matéria corpórea que sustenta os predicados. O segundo versará sobre a matéria espiritual que sustenta a forma corpórea. E, posto que a matéria espiritual 
necessita de provas para que se designe o ser e de demonstrações pelas quais se certifique, dado que estas são necessárias para o conhecimento daquilo que ainda não é evidente por si mesmo, assim, aqui é necessário um terceiro tratado que se ocupe da demonstração das substâncias simples. E também é necessário que haja um quarto tratado no qual se trate da busca do conhecimento da matéria e da forma nas substâncias simples. Quando tivermos completado a investigação nesses quatro tratados, será preciso que estudemos a matéria e a forma em si, devendo ser este, pois, o quinto tratado, próprio para a consideração deste propósito. Assim, tudo o que devemos examinar sobre a matéria e a forma será encontrado nestes cinco tratados que determinamos, e aí está tudo o que este livro contém.

\section{0.}

D. - Já que dividiste tão bem os tratados para a especulação da matéria e da forma, iniciemos, pois, aprofundando a investigação daquilo que neles pretendemos estudar.

M. - O ser da matéria universal e o da forma universal não são conhecidos de uma só maneira.

D. - Explica-me essas diferentes maneiras.

M. - A primeira vista, são dois os modos pelos quais podemos conhecer o ser da matéria e da forma universais. Um é o universal comum e o outro é o particular e próprio.

D. - Como pode ser conhecido o ser da matéria e da forma de acordo com o modo universal?

M. - Todas as coisas que quisermos conhecer por suas características, serão buscadas pelas propriedades que lhe são inseparáveis. Quando tivermos conhecido estas propriedades, e o que elas são, então saberemos que a coisa da qual são propriedades existe.

D. - Dá-me um exemplo disso que dizes.

M. - Se existe uma matéria universal de todas as coisas, estas são as propriedades que lhe são inerentes: existe por si, tem uma única essência, é aquilo que sustenta a diversidade, e confere a qualquer coisa sua essência e seu nome.

D. - Qual é a prova de que estas propriedades são inerentes à matéria universal e se referem a ela?

M. - É necessário que a matéria universal possua estas propriedades se ela possuir um ser.

D. - E como é isso?

M. - A matéria deve possuir ser, pois o que não é não pode ser matéria daquilo que é. Diz-se que ela é subsistente por si para que a razão de seu ser não vá até o infinito, o que ocorreria se ela não existisse em si mesma. Diz-se que é de uma única essência, porque não buscamos mais do que uma só matéria em todas as coisas. Que suporta a diversidade porque a diversidade procede das formas e as formas não são existentes por si; e que confere a todas as coisas substância e 
nome porque, em sendo aquela que sustenta todas as coisas, é preciso que esteja em todas e, existindo em todas, é preciso que confira a todas sua essência e seu nome.

11.

D. - Já me é claro que a matéria universal deve possuir estas propriedades.

M. - Procura por estas propriedades em tudo aquilo que existe, e se as encontrares, terás encontrado a matéria primeira.

D. - E como devo procurar?

M. - Pela análise intelectual, ou seja, abstraindo a forma daquilo que existe, separando uma forma de outra e caminhando do manifesto ao oculto, até que chegues à forma além da qual não há outra forma, e esta forma, que precede a todas as formas, é a forma daquilo que a sustenta em si mesma.

D. - Dá-me um exemplo.

M. - Um exemplo disso é o céu. A forma que primeiro nos chega é a cor; a seguir a figura, depois a corporeidade, a seguir a substancialidade e depois as demais, ou seja, as percepções espirituais, até que chegues ao conceito da coisa criada única e que existe em si e sustenta todas estas formas. E então encontrarás esta coisa descrita pelas propriedades anteriormente indicadas e descobrirás que ela é o limite oculto, por trás do qual não há mais limite, a não ser um: O Criador; Louvado seja Seu nome!

D. - Já separei umas formas das outras, naquilo que existe, e caminhei do visível ao invisível e cheguei ao fim oculto, além do qual não há outro fim, conforme disseste.

M. - Agora é necessário voltar do fim oculto ao manifesto, e deste a outros mais manifestos até que chegues ao ponto do qual partiste; e encontrarás as propriedades do fim oculto acompanhando-te e indo contigo do oculto ao manifesto.

D. - Já procurei as propriedades naquilo que existe e as encontrei infusas e atravessando, desde o ser maior até o menor e cheguei até o indivíduo que não se divide, mas não vi por causa disso necessidade de que exista uma matéria universal que sustente todas as coisas e que seja uma coisa distinta delas.

M. - Não aceitaste ser uma propriedade da matéria universal conferir a todas as coisas sua substância e seu nome? E de onde as coisas que existem obteriam esta propriedade, se não estivesse ali a matéria universal para conferi-la?

\section{2.}

D. - É como dizes. Mas, como seria esta matéria distinta das coisas que existem?

M. - Não é possível que a essência da matéria seja distinta das coisas que existem, mas as coisas que existem se tornam distintas da matéria pelas formas que a elas se acrescentam, isto é, pelas diferenças que a diversificam; donde se conclui que a diversidade que existe entre as coisas que existem somente se faz 
manifesta pelas formas manifestas; do mesmo modo, a diversidade oculta que nelas existe, provém somente das formas ocultas. Logo, a diversidade procede somente das formas das coisas que são; mas a essência oculta que recebe estas formas é a matéria primeira universal, una e sem diferenças.

D. - Dá-me um exemplo disso.

M. - Observa braceletes de ouro e colares de ouro e coloca-os no lugar das coisas que existem. Ainda que os vejas diferentes pelas suas formas, sabes que é uma mesma matéria que os sustenta, não sendo a essência da matéria de um diferente da essência da matéria dos outros. Saberás assim que as coisas que existem são diversas pelas formas, mas é una a matéria que as sustenta e que a essência desta não é distinta da essência daquelas.

13.

D. - Tu me fizeste encontrar a matéria universal, posto que encontrei suas propriedades nas coisas que existem. Faz com que eu encontre também, do mesmo modo, a forma universal.

M. - Examina do mesmo modo as propriedades da forma universal que são: subsistir em outro, aperfeiçoar ${ }^{3}$ a essência daquilo no qual se encontra e conferirlhe o ser. Se encontrares estas propriedades nas formas das coisas que são, terás chegado já à forma universal.

D. - Por que razão afirmas que estas propriedades são inerentes à forma universal?

M. - A forma necessita ser sustentada, pois se não fosse sustentada, sustentaria, e então não seria forma, mas matéria, e teria o conceito daquela. Aperfeiçoar a essência na qual se encontra e conferir o ser compete à forma, pois a coisa não é tal como é, a não ser pela forma.

D. - Não dissemos antes que também a matéria possui o ser?

M. - Só dissemos que a matéria possui o ser quando lhe conferimos uma forma espiritual. A matéria não possui em si o ser que obtém quando a forma lhe é acrescentada. Esse é o ser em ato. De resto, quando dizemos que a matéria é, o ser que possui é o ser em potência.

D. - Já procurei estas propriedades e já notei que acompanham todas as formas das coisas que existem. Mas, como posso dizer que aqui está a forma universal da qual procedem o ser e a perfeição de todas as formas?

14.

M. - Sugiro que te abstenhas por ora desta questão, pois sua solução virá depois.

Ibn Gabirol retoma a noção aristotélica da perfeição por passar da potência ao ato. 
D. - Explica-me então agora, o ser da matéria universal e da forma universal, de acordo com o modo próprio que me anunciaste antes, pois já me ficou claro de acordo com o modo comum.

M. - Observa as coisas sensíveis naturais, universais e particulares, e não encontrarás nelas outra coisa.

D. - Que exemplo temos nos sensíveis naturais?

M. - Os animais, os vegetais e cada uma das coisas inanimadas são compostos de matéria e forma.

D. - Assim é.

M. - Repara também nas coisas particulares artificiais, como a estátua ou o leito.

D. - Também as observei e são assim.

M. - Assim também ocorre nos universais naturais que são os quatro elementos.

D. - Como assim?

M. - Não vês que cada forma de cada elemento é distinta das outras e que, portanto, é necessário que exista uma forma comum a todas?

D. - Que necessidade te compele a afirmar que além daquelas formas sensíveis há outra que lhes seja comum?

M. - É necessário afirmá-lo porque estas formas são acidentais, não existentes por si. Logo, mantêm uma relação com aquela que é subsistente por si, tal como a que mantêm as formas particulares com as que se sustentam por si.

D. - Já compreendi os substratos das formas particulares, como os humores nas coisas animadas e os elementos nos vegetais e minerais, e como estes se reduzem àqueles, mas, não vi o substrato das formas universais. Por que então devo aceitar que aqui há um substrato da mesma maneira que aceitei que havia substratos ali?

M. - Tu viste os quatro elementos nos seres animados, nos vegetais e nos minerais?

D. - Não, mas vi os seres animados e então os reduzi a eles.

M. - Assim verás também que estas formas universais se reduzem também a seus substratos e que será necessário que seu substrato seja uno.

D. - Compreendi, mas acrescenta algo à tua explicação.

M. - A prova disso é a oposição das qualidades.

D. - Como assim?

M. - Por que as qualidades rechaçam a mistura e a aproximação. Portanto, é necessário que exista algo distinto delas que as una e as mantenha unidas. Não estou falando aqui de conjunção de ações nem de retenção de obras, mas conjunção e manutenção no lugar, porque a ação convém ao agente, não ao substrato.

D. - Eu compreendi, mas acrescenta ainda mais alguma explicação.

M. - Aceitas que a geração só ocorre pelos contrários?

D. - Não digo outra coisa. 
M. - Sabes que se não existisse aqui uma coisa que fosse o sujeito dos contrários, a substância seria resultado da não-substância e aquilo que não é substância seria anterior à substância.

D. - Como assim?

M. - Todo elemento que é substância provém de outro elemento. Assim, os animais, os vegetais e os minerais são substâncias feitas a partir dos elementos. Se não existisse um substrato no qual se verificasse a geração e se este não existisse previamente na realidade na qual se dá a geração ${ }^{4} .$. Disso se deduz necessariamente então o que eu antes havia dito.

D. - Já entendi, mas explica-me mais.

\section{5.}

M. - Os elementos também são diversos enquanto tais. E são semelhantes enquanto corpos. Em conseqüência, o corpo deve ser o seu substrato.

D. - Não deve ser de outro modo. Se estes elementos são semelhantes na corporeidade, como disseste, é preciso que o corpo seja o substrato das formas dos elementos. Mas, o que dizes da natureza deste corpo?

M. - Disso falaremos depois, quando tivermos estudado este corpo, e tivermos separado sua propriedade, que é a quantidade, de seu substrato, que é a substância. Então será claro para ti que a relação do substrato com o corpo que sustenta as propriedades dos elementos, é como a deste corpo com aquelas formas, e será claro, por esta consideração, o que existe depois das demais substâncias que são substrato para si mesmas, e subsistem umas nas outras, pelo que chegarás ao substrato primeiro, que é a matéria universal da qual tratamos, e conhecerás as relações que existem entre estes substratos e os predicados ${ }^{5}$, que são as substâncias intermediárias entre o supremo oculto que é a matéria primeira, e o supremo manifesto que são as formas sensíveis.

D. - Retornemos ao que falávamos do corpo como substrato das formas dos elementos.

16.

M. - Manifesto é para ti que os elementos são diversos nas formas, isto é, nas quatro qualidades, mas que concordam quanto ao corpo e está claro para ti que este corpo é uno, substrato de quatro formas?

D. - Sim, isto está claro.

M. - Estas formas universais serão, pois, nos elementos, como as formas particulares naquilo que deles se constitui?

D. - É preciso que assim seja.

4 No original, falta uma parte do texto, para que o silogismo se completasse.

"Ista subjecta et praedicata". 
M. - Igualmente, o corpo que é o substrato daquelas formas universais será da mesma maneira que os elementos que são o substrato das formas particulares.

D. - É também preciso que assim seja.

M. - Toma isto com regra e considera, de acordo com ela, o que disso se segue.

D. - Penso que com isso te referes ao céu, pois concorda na corporeidade com os elementos, pelo que devemos julgá-lo do mesmo modo.

M. - Não deve ser de outra maneira.

D. - Assim é. Mas, como posso afirmar que sejam distintas a matéria e a forma em uma coisa na qual matéria e forma nunca se separam?

M. - Quando vires outra forma semelhante que subsiste em uma matéria que é diferente daquela, saberás então, através disso, que a matéria é diferente da forma, dado que, se fossem uma mesma coisa, não poderiam se separar.

\section{7.}

M. - Além disso, fixaremos depois a certeza da separação da forma e da matéria, quando consideremos a substância que sustenta os nove predicados.

D. - Já entendo o que dizes.

M. - Logo, a forma que se sustenta no corpo do céu será como as formas universais subsistentes nos corpos elementares, de modo que estas mesmas sejam como as formas particulares subsistentes nos compostos dos elementos.

D. - É necessário que assim seja. Mas, por que separas o corpo do céu do corpo das coisas naturais, quando concordam na quantidade, e é preciso por isso que ambos sejam corpos?

M. - Certamente, é verdade que o corpo do céu e o dos elementos são um corpo, posto que concordam na quantidade; mas a diferença entre o corpo do céu e dos elementos não provém desta parte, mas consiste em que o corpo do céu não recebe as qualidades dos elementos, nem geração nem corrupção,e que a forma do céu é distinta das formas dos elementos.

D. - Como é possível que afirmemos que o corpo do céu e o dos elementos são um corpo, quando o corpo do céu não recebe geração nem corrupção e o corpo dos elementos as recebe?

M. - Do mesmo modo que podemos dizer que o corpo dos elementos é uno, ainda que estes difiram nas qualidades.

D. - Que responderias àquele que negue que o céu é corpo?

M. - Não é possível negar que o céu seja corpo, posto que as propriedades e as diferenças de corpo são nele visíveis. O que alguém poderá objetar é que seja um corpo como os demais corpos, mas agora não convém que disputes sobre isto. Diz-me, pois, que frutos obtiveste dos raciocínios precedentes?

D. - Aprendi quatro modos de matéria e outros quatro de forma.

M. - Quais são? 
D. - Matéria particular artificial, matéria particular natural, matéria universal natural que recebe a geração, e matéria celeste. Por outro lado, a cada uma destas matérias corresponde a forma sustentada por elas.

M. - Entendeste-o bem. Mas, há que entender ainda que estes quatro modos da matéria e da forma, ainda que diversos, concordam na idéia de matéria e de forma.

D. - Assim é.

M. - E nas coisas sensíveis, nada mais há do que isto?

D. - Não, nada mais há.

M. - Já concordamos que nas coisas sensíveis naturais, universais e particulares, nada mais há do que matéria e forma.

D. - Assim é.

M. - As partes se juntam e formam um todo; a matéria e a forma são partes, portanto, devem unir-se e formar um todo.

D. - Como podem juntar-se, em sendo diversas?

M. - Por acaso os elementos, ainda que sejam diversos, não concordam em que são corpos? Pois igualmente, as formas concordam em serem formas do corpo, logo as formas, em espécie, são uma, isso é, forma sensível, enquanto que nos indivíduos são múltiplas, isto é, em cada um deles.

D. - Assim é.

M. - Logo, nas coisas sensíveis deve haver matéria universal, isto é, corpo; e forma universal, a saber, tudo aquilo que é sustentado pelo corpo.

D. - É necessário que assim seja.

M. - Posto que, por esta discussão do primeiro tratado, já obtiveste a certeza de que nas coisas sensíveis nada há senão matéria, isto é, o corpo universal, e forma, que é tudo aquilo que se sustenta neste corpo, consideremos, pois, no segundo tratado, o que é aquilo que se vem depois do corpo sensível, isto é, a substância que sustenta a quantidade. Este será o início de nossa investigação acerca das substâncias inteligíveis. 